\title{
Ionic liquid as separation enhancer in thin-layer chromatography of biosurfactants: mutual separation of sodium cholate, sodium deoxycholate and sodium taurocholate
}

\author{
Ali Mohammad ${ }^{*}$ and Rizwana Mobin
}

\begin{abstract}
Background: Physiological biosurfactants plays an important role in digestion of lipids and cholesterol also emulsifies fat-soluble vitamins.

Methods: A new green thin-layer chromatographic system comprising ionic liquid (1-methylimidazolium chloride) impregnated silica gel $\mathrm{G}$ and 2-methyl tetrahydrofuran as stationary and mobile phases was found to be most suitable for the separation of ternary mixture of biosurfactants (sodium cholate, sodium deoxycholate and sodium taurocholate). The surface structure and chemical composition of silica gel $\mathrm{G}$ modified by impregnation with 1-methylimidazolium chloride were examined with the aid of scanning electron microscopy and energy-dispersive X-ray spectrophotometry, respectively.
\end{abstract}

Results: Compared to plain silica gel, enhanced separation efficiency of ionic liquid impregnated silica gel was observed for the resolution of biosurfactants from their mixture. Chromatographic parameters such as $\Delta R_{\mathrm{F}}$, separation factor $(a)$ and resolution $\left(R_{\mathrm{S}}\right)$ for the separation were calculated. Effect of foreign substances (metal cations, inorganic anions, vitamins, amino acids and non-ionic surfactants as impurities) on the separation of surfactants was also examined. Effects of concentration level of 1-methylimidazolium chloride as impregnant and its substitution by other ionic liquids (1,2,3-trimethylimidazoliummethyl sulphate, 1-ethyl-3-methylimidazolium tetrafluoroborate) were also studied to decide the optimum experimental conditions for better separation possibilities. The limits of detection of sodium cholate, sodium deoxycholate and sodium taurocholate were calculated.

Conclusion: A new green thin-layer chromatographic system comprising ionic liquid (1-methylimidazolium chloride) impregnated silica gel $\mathrm{G}$ and 2-methyl tetrahydrofuran as stationary and mobile phases provide the most suitable environment for the separation of ternary mixture of biosurfactants.

Keyword: Thin-layer chromatography; lonic liquid; Biosurfactants; SEM; EDX

\section{Background}

Bile salts commonly occurring as sodium salts of bile acid and produced in the liver of mammals are known as primary bile acids, and those produced by the bacteria present in the colon are called secondary bile acids. Because of micelles' forming properties, bile salts [sodium cholate (SC), sodium deoxycholate (SDC) and sodium taurocholate (STC)] have been popular as

\footnotetext{
* Correspondence: alimohammad08@gmail.com

Department of Applied Chemistry, Faculty of Engineering and Technology, Aligarh Muslim University, A.M.U, Aligarh 202002, Uttar Pradesh, India
}

physiological biosurfactants (Santhanalakshmi et al. 2001; Matsuoka and Moroni 2002; Hofmann and Mysels 1987; Selvam et al. 2009). These biosurfactants play an important role in (a) digestion of lipids and cholesterol, (b) emulsifying fat-soluble vitamins to enable their absorption in the intestine and (c) excretion of bilirubin. Biosurfactants have found use in medicines and cosmetics as emulsifying and dispersing agents (Santhanalakshmi et al. 2001; Selvam et al. 2009). SC and SDC being water-soluble mild ionic detergents are used 
for the isolation of membrane protein and lipids. In affinity chromatography $\mathrm{SC}$ is used for preventing non-specific binding. It is also used in cell culture media supplements Sodium Cholate, Pierce Biotechnology, USA. SDC is used as a non-surgical cosmetic medicinal treatment in mesotherapy injection and acts as a photo-resistant component in microlithography (Nanda 2011; Matarasso and Pfeifer 2009; Kim et al. 2000). Thus, analysis of these biosurfactants has been important because of their physiological importance.

Various analytical methods have been used in separation science, but thin-layer chromatography (TLC) is the most popular analytical tool used for separation because it is simple, rapid, versatile and cost-effective (Mohammad and Hina 2005; Mohammad and Bhawani 2008; Mohammad et al. 2010; Mohammad et al. 2013). Several inorganic, organic and aqueous-organic mobile phases and different stationary phases have been used in TLC analysis of surfactants (Mohammad and Agrawal 2001; Mohammad et al. 2002; Touchstone 1992; Gocan 2002). Most of mixed aqueous-organic and organic solvents previously used in chromatographic analysis need to be replaced by environmentally benign solvent systems in order to reduce their adverse impact on the environment.

Our aim of the present study was to achieve important separations of biosurfactants making TLC green by using environmental friendly mobile phase and silica gel modified with ionic liquid as stationary phase. Ionic liquids (ILs) are organic compounds, which exist in liquid form at room temperature, and have received much attention for their use in chemical industries due to various salient features such as good thermal stability, non-volatility and non-generating harmful volatile organic compounds (VOCs) as products. ILs provide good medium to solubilise $\mathrm{H}_{2}, \mathrm{O}_{2}, \mathrm{CO}$ and $\mathrm{CO}_{2}$ gases and easily interact with other compounds via hydrogen bonding and electrostatic, dipolar, dispersive, pi-pi and n-pi bonding (Mallakpour and Dinari 2012).

In the present study, 1-methylimidazolium chloride ionic liquid is introduced in silica gel stationary phase which modifies the surface structure and provides better resolution of biosurfactants (SC, SDC and STC) in the presence of 2-methyltetrahydrofuran, a green alternative solvent for tetrahydrofuran as mobile phase. The use of green solvents in mobile as well as in stationary phases is a novel approach to develop environmental friendly green TLC method. It fulfils the growing demand of making analytical process greener. The proposed method was successful to identify SDC in formulated sample.

\section{Methods}

All experiments were performed at $25 \pm 2^{\circ} \mathrm{C}$.

\section{Apparatus}

A TLC applicator was used for coating silica gel on $20 \times$ $3.2 \mathrm{~cm}$ glass plates and chromatography was performed in $24 \times 6 \mathrm{~cm}$ glass jars. A glass sprayer was used to spray reagent on the plates to locate the position of the spot of the analyte.

\section{Chemicals and reagents}

Silica gel G (Thermo Fisher Scientific, Mumbai, India), alumina, kieselguhr, 2-methyltetrahydrofuran $(\mathrm{CDH}, \mathrm{New}$ Delhi, India) and 1-methylimidazolium chloride, 1,2, 3-trimethylimidazoliummethyl sulphate and 1-ethyl-3methylimidazolium tetrafluoroborate (Sigma-Aldrich, St. Louis, MO, USA) were used. All the reagents used were of analytical grade.

\section{Surfactants studied}

Sodium cholate, sodium deoxycholate, sodium taurocholate, Tween 20, brij35, Tween 80, Triton X-100 and formaldehyde purchased from $\mathrm{CDH}$ (New Delhi, India) were used. All the surfactants were used as received.

\section{Test solutions}

Solution of biosurfactants was prepared in double-distilled water (DDW) to give a concentration of $5 \%(w / v)$.

\section{Stationary phases}

$S_{1}$ - Silica gel $G$

$\mathrm{S}_{2}-\mathrm{S}_{5}$ - Silica gel G impregnated with 0.1, 1.0, 5.0 and

$10.0 \%$ 1-methylimidazolium chloride (aq), respectively.

$\mathrm{S}_{6}$ - Silica gel G impregnated with $5.0 \%$ 1,2,3-

trimethylimidazoliummethyl sulphate (aq)

$\mathrm{S}_{7}$ - Silica gel G impregnated with 5.0\% 1-ethyl-3-

methylimidazolium tetrafluoroborate (aq)

\section{Mobile phases}

The mobile phases used were as follows:

$\mathrm{M}_{1}$ - 5.0\% 1-Methylimidazolium chloride (aq)

$\mathrm{M}_{2}$ - Pure 2-methyltetrahydrofuran (purity, 99.0\%)

$\mathrm{M}_{3}$ - Pure acetone (purity, 99.0\%)

$\mathrm{M}_{4}$ - Pure dimethyl sulfoxide (DMSO; purity, 99.0\%)

All the solvents were used as received.

\section{Detection reagent}

For detection of anionic surfactants, 100-mg pinacryptol yellow (Fluka, Sigma-Aldrich, Steinheim, Germany) was dissolved in 100-mL hot water and sprayed on TLC plates to visualise yellow to orange fluorescence spots under long wavelength UV light (366 nm). 


\section{Preparation of 1-methylimidazolium chloride impregnated TLC plates}

Both pre-impregnation and post-impregnation methods described below as (a) and (b) were used for obtaining 1-methylimidazolium chloride impregnated silica TLC plates.

(a) In pre-impregnation methods, plates were prepared by mixing silica gel $\mathrm{G}$ and aqueous solution of 1 methylimidazolium chloride of desired concentration $(0.1 \sim 10.0 \%)$ in $3: 1$ ratio. The resultant slurry was mechanically shaken for $15 \mathrm{~min}$ and then coated onto glass plates with the help of a TLC applicator to give a layer of $0.25-\mathrm{mm}$ thickness. The plates were first air dried at room temperature and then activated by heating at $100{ }^{\circ} \mathrm{C}$ for $1 \mathrm{~h}$. After activation, the plates were kept in an air-tight chamber until used.

(b)In post-impregnation method, activated silica gel plates were impregnated with desired concentration of aqueous solution of 1-methylimidazolium chloride $(0.1 \sim 10.0 \%)$ by dipping silica gel plates in a solution of impregnate for a specific time period (20 min) followed by drying of plates at room temperature $\left(25^{\circ} \mathrm{C}\right)$ and activation by heating for $1 \mathrm{~h}$ at $100^{\circ} \mathrm{C}$. After activation, the plates were kept in an air-tight chamber until used.

In the present study, the TLC plates obtained by preimpregnated method found better from a chromatographic point of view in terms of yielding more compact and well-resolved spots for biosurfactants. For example, the higher value $(3.2 \mathrm{~cm})$ of separated distance between the resolved spots of SDC and SC from their mixture on pre-impregnated TLC plates compared to the value of $2.1 \mathrm{~cm}$ on post-impregnated TLC plates is evident for better chromatographic performance of pre-impregnated method. Therefore, the detailed study was undertaken using pre-impregnating TLC plates.

\section{Procedure}

The biosurfactant solutions $(0.1 \mu \mathrm{l})$ were spotted on nonimpregnated and impregnated TLC plates with micropipette at approximately $2 \mathrm{~cm}$ above the lower edge of the non-impregnated and impregnated TLC plates. The spots were dried at room temperature $\left(25 \pm 2^{\circ} \mathrm{C}\right)$. The glass jars containing the mobile phase were covered with lids and left for $10 \mathrm{~min}$ for saturation before introducing the plates for development. The plates were developed with listed solvent systems $\left(\mathrm{M}_{1}-\mathrm{M}_{4}\right)$ to a distance of $10 \mathrm{~cm}$ from the origin in all cases. After development, the plates were detected by a spraying solution of pinacryptol yellow and viewing the location of biosurfactants under UV light (366 nm).
For the separation of biosurfactant mixtures, equal volume of each biosurfactant was mixed and $0.1 \mu \mathrm{L}$ of the resultant mixture was applied onto 5\%(aq) 1methylimidazolium chloride impregnated TLC plates $\left(S_{4}\right)$. The plates were developed with $M_{2}$, the spots were detected and $R_{\mathrm{F}}$ values of the separated spots of the biosurfactants were calculated.

To understand the separation behaviour of biosurfactants in different impregnating liquids, 1-methylimidazolium chloride in $\mathrm{S}_{4}$ was replaced with 1,2,3-trimethylimidazolium methyl sulphate and 1-ethyl-3-methylimidazolium tetrafluoroborate. The resultant stationary phase systems $\left(S_{6}\right.$ and $\left.S_{7}\right)$ were used for the chromatography of biosurfactants. $R_{\mathrm{F}}$ values obtained with the use of these stationary phases were compared with those obtained with $S_{4}$.

Surface structure and chemical composition of pure silica gel and silica gel impregnated with 5\%(aq) 1methylimidazolium chloride were studied with scanning electron microscopy (SEM) and energy-dispersive X-ray spectrophotometer (EDX).

In order to examine the mobility pattern of biosurfactants on $S_{4}$, acetone $\left(M_{3}\right)$ and dimethyl sulfoxide $\left(M_{4}\right)$ were also used as eluents.

For investigating the interference of the presence of metal cations, metal anions, vitamins amino acids and non-ionic surfactants as impurities on the resolution of mixture, $0.1 \mu \mathrm{L}$ of standard test mixture of biosurfactant solutions was spotted on the impregnated TLC plate followed by spotting of $0.1 \mu \mathrm{L}$ of the metal cations, metal anions, vitamins and amino acids and non-ionic surfactants being considered as impurities. The plates were developed with $\mathrm{M}_{2}$ and detected, and $R_{\mathrm{F}}$ values of the separated biosurfactants were calculated.

The limit of detection of separated biosurfactants were determined by spotting $0.1 \mu \mathrm{L}$ of SC, SDC and STC of different concentrations on the impregnated TLC plates which were developed with selected mobile phase $M_{2}$, and the spots were visualised using pinacryptol yellow reagent under UV light. This process was repeated with successive reduction in concentration of biosurfactant until no detection of biosurfactant was possible. The amount of biosurfactant just detectable was taken as the detection limit.

\section{Results and discussion}

Thin-layer chromatography of three biosurfactants was performed on pure silica gel plate and silica gel G impregnated with different concentration levels $(0.1 \sim 10 \%)$ of 1 methylimidazolium chloride using four mobile phases $\left(\mathrm{M}_{1}-\mathrm{M}_{4}\right)$ in order to select a novel TLC system for achieving separation of three coexisting biosurfactants. The results obtained have been presented in Tables 1, 2, 3, 4, 5 and 6 and Figures 1, 2, 3, 4, 5 and 6 and are discussed below. 
Table 1 Mobility of biosurfactants in terms of $\boldsymbol{R}_{\mathrm{F}}$ values on different stationary phases

\begin{tabular}{lllllll}
\hline Biosurfactants & \multicolumn{6}{l}{$\boldsymbol{R}_{\mathbf{F}}$ value } \\
\cline { 2 - 7 } & $\mathbf{S}_{\mathbf{1}}$ & $\mathbf{S}_{\mathbf{2}}$ & $\mathbf{S}_{\mathbf{3}}$ & $\mathbf{S}_{\mathbf{4}}$ & $\mathbf{S}_{\mathbf{5}}$ & \\
& $\mathbf{M}_{\mathbf{1}}$ & $\mathbf{M}_{\mathbf{2}}$ & $\mathbf{M}_{\mathbf{2}}$ & $\mathbf{M}_{\mathbf{2}}$ & $\mathbf{M}_{\mathbf{2}}$ & $\mathbf{M}_{\mathbf{2}}$ \\
\hline Sodium cholate & $\mathrm{ND}$ & 0.54 & 0.48 & 0.53 & 0.48 & $\mathrm{ND}$ \\
Sodium deoxycholate & 0.02 & 0.65 & 0.76 & 0.83 & 0.89 & $\mathrm{ND}$ \\
Sodium taurocholate & $\mathrm{ND}$ & 0.02 & 0.03 & 0.02 & 0.03 & 0.02 \\
\hline
\end{tabular}

A. Unimpregnated silica gel TLC plates $\left(\mathrm{S}_{1}\right)$

(a) On pure silica static flat phase $\left(\mathrm{S}_{1}\right)$ using $5 \%(\mathrm{aq})$ 1-methylimidazolium chloride $\left(\mathrm{M}_{1}\right)$ as mobile phase, SDC remains at the point of application $\left(R_{\mathrm{F}} \sim 0.02\right)$ whereas SC and STC were not detected.

(b)SC $\left(R_{\mathrm{F}}=0.54\right)$ and SDC $\left(R_{\mathrm{F}}=0.65\right)$ exhibit high mobility and STC remains at the point of application $\left(R_{\mathrm{F}} \sim 0.02\right)$ with 2-methyltetrahydrofuran $\left(\mathrm{M}_{2}\right)$ as mobile phase and $S_{1}$ as stationary phase. Binary separations of these biosurfactants were achieved with the use of $S_{1}$ and $M_{2}$ as stationary and mobile phases (Table 1).

B. Impregnated silica gel TLC plates $\left(\mathrm{S}_{2}-\mathrm{S}_{5}\right)$

In order to obtain improved separation possibilities, silica gel $\mathrm{G}$ was impregnated with different concentrations of ionic liquid (1-methylimidazolium chloride; $0.1 \sim 10 \%$ ) and the resultant stationary phases $\left(\mathrm{S}_{2}-\mathrm{S}_{5}\right)$ were used for chromatographic analysis of biosurfactants.

(a) SC and SDC showed differential migration $\left(R_{\mathrm{F}}=0.48,0.76\right)$ while STC remains at the point of application $\left(R_{\mathrm{F}} \sim 0.03\right)$ on using $\mathrm{S}_{2}$ (silica gel impregnated with $0.1 \%(\mathrm{aq}) 1$-methylimidazolium IL) as stationary phase and $\mathrm{M}_{2}$ as mobile phase. Though the mutual separation of these SC, SDC and STC was possible with this TLC system, but the spots lack clarity and compactness; hence, concentration of impregnant was increased up to $10 \%$.

Table 2 Effect of concentration of 1-methylimidazolium chloride on $\Delta \boldsymbol{R}_{\mathrm{F}}$ and separation factor (a) of biosurfactants

\begin{tabular}{|c|c|c|c|c|}
\hline \multirow{3}{*}{$\begin{array}{l}\text { Concentration of } 1- \\
\text { methylimidazolium chloride }\end{array}$} & \multicolumn{4}{|c|}{ SDC-SC-STC } \\
\hline & \multicolumn{2}{|c|}{ SDC-SC } & \multicolumn{2}{|c|}{ SC-STC } \\
\hline & $\Delta R_{\mathrm{F}}$ & $a$ & $\Delta R_{\mathrm{F}}$ & $a$ \\
\hline 0.1\% 1-Methylimidazolium chloride & 0.30 & 3.48 & 0.45 & 29.9 \\
\hline 1\% 1-Methylimidazolium chloride & 0.46 & 8.5 & 0.35 & 28.8 \\
\hline 5\% 1-Methylimidazolium chloride & 0.31 & 4.15 & 0.45 & 29.9 \\
\hline 10\% 1-Methylimidazolium chloride & 0.00 & 0.00 & 0.02 & 0.00 \\
\hline
\end{tabular}

Table 3 Effect of substitution of 1-methylimidazolium chloride with different ionic liquids on $\boldsymbol{R}_{\mathrm{F}}$ of separated biosurfactants

\begin{tabular}{llll}
\hline Different ionic liquids & \multicolumn{3}{l}{$\boldsymbol{R}_{\mathbf{F}}$ value } \\
\cline { 2 - 4 } & SDC & SC & STC \\
\hline 1-Methylimidazolium chloride & 0.89 & 0.48 & 0.03 \\
1, 2, 3-Trimethylimidazoliummethyl sulphate & 0.53 & 0.36 & 0.02 \\
1-Ethyl-3-methylimidazolium tetrafluoroborate & 0.92 & 0.92 & 0.03 \\
\hline
\end{tabular}

(b)At $1.0 \%$ concentration of impregnant $\left(S_{3}\right)$, the mutual separation of three surfactants SC $\left(R_{\mathrm{F}}=0.53\right)$, SDC (0.83) and STC $\left(R_{\mathrm{F}} \sim 0.02\right)$ was also possible with slightly improved compactness of spots.

(c) The better resolved spots of surfactants (SC, SDC and STC; $R_{\mathrm{F}}=0.48,0.89$ and 0.03) from their threecomponent mixture were realised with $\mathrm{M}_{2}$ mobile phase and silica gel $\mathrm{G}$ impregnated with $5 \%(\mathrm{aq})$ 1-methylimidazolium chloride $\left(\mathrm{S}_{4}\right)$ stationary phase. Therefore, this TLC system was considered the best system for the resolution of coexisting SC, SDC and STC biosurfactants.

(d)The higher concentration of impregnant exceeding to $5.0 \%$ was not found suitable because SC and SDC could not be detected on the use of silica gel impregnated with $10 \%(\mathrm{aq}) 1$-methylimidazolium chloride $\left(\mathrm{S}_{5}\right)$ as stationary phase in combination with $\mathrm{M}_{2}$ mobile phase (Table 2).

(e) Thus, the TLC system $\left(\mathrm{S}_{4}-\mathrm{M}_{2}\right)$ was most favourable for the resolution of coexisting SC, SDC and STC biosurfactants (Figure 1).

C. Silica gel impregnated with other ionic liquids $\left(\mathrm{S}_{6}-\mathrm{S}_{7}\right)$

In order to examine the effect of nature of ionic liquid on the mobility of biosurfactants, 1,2,3-trimethylimidazoliummethyl sulphate and 1-ethyl-3-methylimidazolium tetrafluoroborate were used as impregnating liquid in place of 1-methylimidazoilum chloride and the resultant stationary phases $S_{6}$ and $S_{7}$, respectively, were used for chromatography of surfactants.

Table 4 Effect of substitution of 1-methylimidazolium chloride on $\Delta R_{\mathrm{F}}$ and separation factor (a)

\begin{tabular}{|c|c|c|c|c|}
\hline \multirow[t]{3}{*}{ Different ionic liquids } & \multicolumn{4}{|c|}{ SDC-SC-STC } \\
\hline & \multicolumn{2}{|c|}{ SDC-SC } & \multicolumn{2}{|c|}{ SC-STC } \\
\hline & $\overline{\Delta R_{\mathrm{F}}}$ & $a$ & $\Delta R_{\mathrm{F}}$ & $a$ \\
\hline 1-Methylimidazolium chloride & 0.31 & 4.15 & 0.45 & 29.9 \\
\hline 1, 2, 3-Trimethylimidazoliummethyl sulphate & 0.17 & 2.01 & 0.34 & 27.6 \\
\hline 1-Ethyl-3-methylimidazolium tetrafluoroborate & 0.00 & 1.00 & 0.89 & 37.5 \\
\hline
\end{tabular}


Table 5 Mobility of biosurfactants in terms of RF value on $\mathrm{S}_{4}$ with different mobile phases

\begin{tabular}{llll}
\hline Biosurfactants & \multicolumn{3}{l}{$\boldsymbol{R}_{\mathbf{F}}$ value on $\mathbf{S}_{\mathbf{4}}$} \\
\cline { 2 - 4 } & $\mathbf{M}_{\mathbf{2}}$ & $\mathbf{M}_{\mathbf{3}}$ & $\mathbf{M}_{\mathbf{4}}$ \\
\hline Sodium cholate & 0.48 & 0.81 & 0.93 \\
Sodium deoxycholate & 0.89 & 0.76 & 0.89 \\
Sodium taurocholate & 0.03 & $\mathrm{ND}$ & $\mathrm{ND}$ \\
\hline
\end{tabular}

(a) Compared to $\mathrm{S}_{4}\left(R_{\mathrm{F}}=0.79\right)$ (Tables 3), the lowering in $R_{\mathrm{F}}$ value of SDC on $\mathrm{S}_{6}\left(R_{\mathrm{F}}=0.53\right)$ results in the inferior resolution of SDC from SC.

(b)Mutual separation of SC and SDC was hampered because both surfactants co-migrate on $S_{7}$ with $M_{2}$ as mobile phase (Tables 3 and 4).

\section{SEM and EDX}

From SEM and EDX images (Figures 2 and 3), it is evident that surface morphology as well as the chemical composition of silica gel are altered due to the incorporation of impregnant (5\%(aq) 1-methylimidazolium chloride). The change in nature of stationary phase on impregnation provides unique opportunities for realising improved separation of biosurfactants.

E. Mobility of biosurfactants with other aprotic polar solvents (acetone and DMSO)

To examine the effect of other aprotic polar solvents on the mobility of these surfactants, acetone $\left(\mathrm{M}_{3}\right)$ and DMSO $\left(\mathrm{M}_{4}\right)$ were selected as commonly used solvents in chromatography. Both SC and SDC showed almost identical mobilities on $\mathrm{S}_{4}$ stationary phase with $\mathrm{M}_{3}$ and $\mathrm{M}_{4}$ mobile phases while STC was not detected in any case (Table 5 and Figure 4). It is therefore concluded that cyclic aprotic polar solvent system is more useful as compared to non-cyclic solvents for chromatographic analysis of surfactants.

F. Effect of replacement of silica with other sorbents

In order to understand the separation pattern of biosurfactants on other adsorbents, 5\%(aq) 1-methylimidazolium chloride impregnated silica gel $G\left(\mathrm{~S}_{4}\right)$ was replaced with

Table 6 Effect of interference on $\Delta R_{F}$, separation $(a)$ and resolution $\left(R_{S}\right)$ factors of the separated biosurfactants

\begin{tabular}{|c|c|c|c|c|c|c|}
\hline \multirow[t]{3}{*}{$\begin{array}{l}\text { Foreign } \\
\text { substances }\end{array}$} & \multicolumn{6}{|c|}{$\begin{array}{l}\text { Ternary mixture } \\
\text { SDC-SC-STC }\end{array}$} \\
\hline & \multicolumn{3}{|l|}{ SDC-SC } & \multicolumn{3}{|l|}{ SC-STC } \\
\hline & $\Delta R_{\mathrm{F}}(0.52)$ & $a(30.0)$ & $R_{\mathrm{S}}(48.0)$ & $\Delta R_{\mathrm{F}}(0.36)$ & $a(14.8)$ & $R_{\mathrm{S}}(57.7)$ \\
\hline \multicolumn{7}{|l|}{ Metal cations } \\
\hline $\mathrm{Cu}^{2+}$ & 0.73 & 128.9 & 100 & 0.20 & 4.75 & 20.0 \\
\hline $\mathrm{Ni}^{2+}$ & 0.66 & 71.8 & 94.4 & 0.21 & 4.09 & 23.3 \\
\hline $\mathrm{Th}^{4+}$ & 0.73 & 148.4 & 102.4 & 0.18 & 4.71 & 20.0 \\
\hline \multicolumn{7}{|l|}{ Metal anions } \\
\hline $\mathrm{Br}^{-}$ & 0.73 & 148.4 & 97.3 & 0.14 & 2.75 & 16.4 \\
\hline $\mathrm{Cl}^{-}$ & 0.61 & 84.4 & 122.0 & 0.26 & 4.83 & 32.5 \\
\hline $\mathrm{CO}_{3}^{2-}$ & 0.62 & 61.0 & 82.6 & 0.21 & 3.31 & 22.1 \\
\hline \multicolumn{7}{|l|}{ Vitamins } \\
\hline Pyridoxine & 0.47 & 47.1 & 72.3 & 0.32 & 4.52 & 35.5 \\
\hline Thymine & 0.43 & 40.1 & 61.4 & 0.31 & 3.93 & 34.4 \\
\hline Ascorbic acid & 0.43 & 21.4 & 53.7 & 0.33 & 4.48 & 36.6 \\
\hline \multicolumn{7}{|l|}{ Amino acids } \\
\hline Lysine & 0.66 & 73.4 & 69.4 & 0.25 & 4.88 & 25.0 \\
\hline Glycine & 0.69 & 122.5 & 115.0 & 0.19 & 3.63 & 22.3 \\
\hline Valine & 0.69 & 122.5 & 86.2 & 0.21 & 4.44 & 22.1 \\
\hline \multicolumn{7}{|c|}{ Non-ionic surfactants } \\
\hline Brij 35 & 0.49 & 51.0 & 65.3 & 0.31 & 4.36 & 34.4 \\
\hline Triton X 100 & 0.55 & 65.3 & 64.7 & 0.29 & 4.68 & 26.3 \\
\hline Tween 20 & 0.53 & 60.4 & 75.7 & 0.35 & 7.36 & 31.1 \\
\hline
\end{tabular}




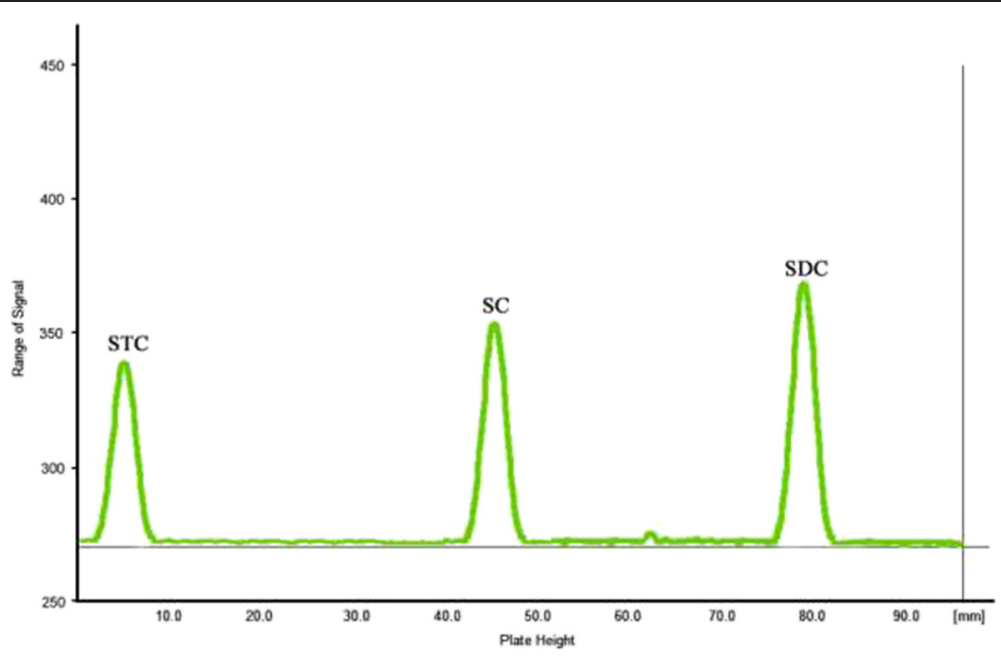

Figure 1 Densitographic presentation of representative ternary separations of anionic surfactants achieved with $\mathrm{M}_{2}$ mobile phase on $\mathrm{S}_{4}$ stationary phase.
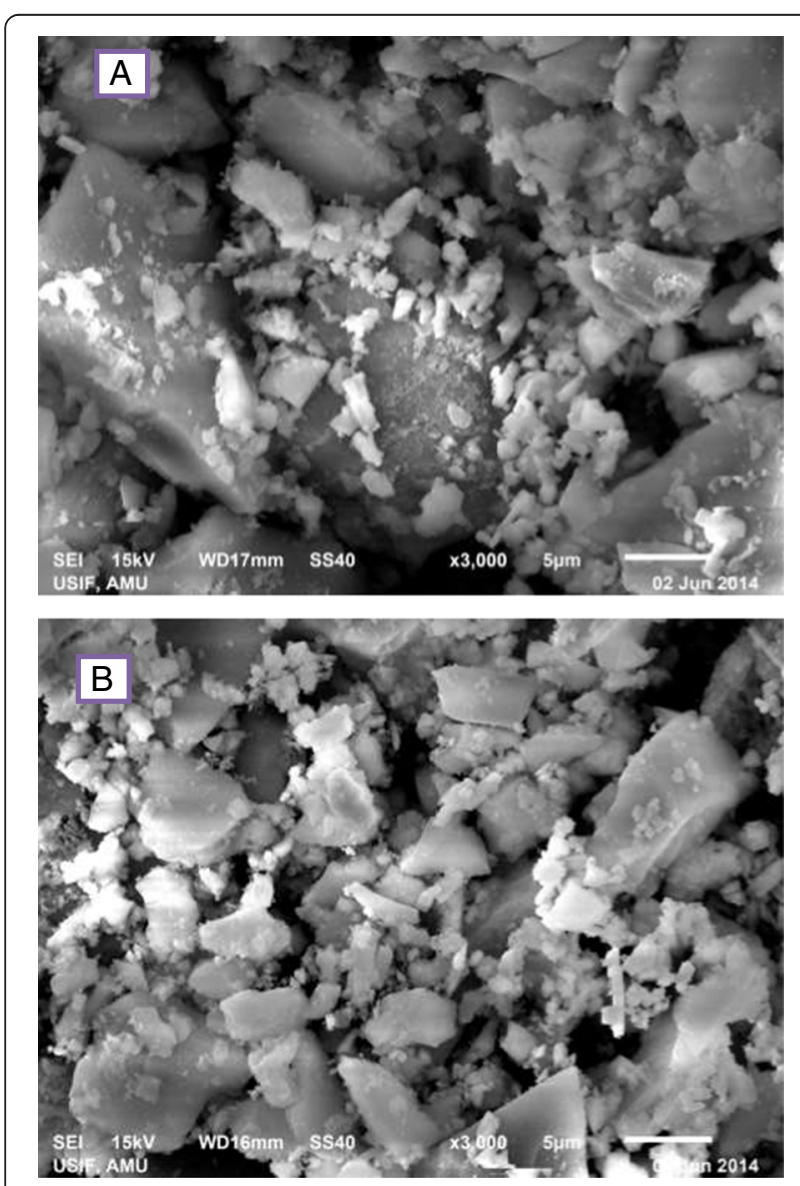

Figure 2 Scanning electron microscopy. SEM of (A) silica gel G and (B) silica gel $\mathrm{G}$ impregnated with 5\% 1-methylimidazolium chloride.

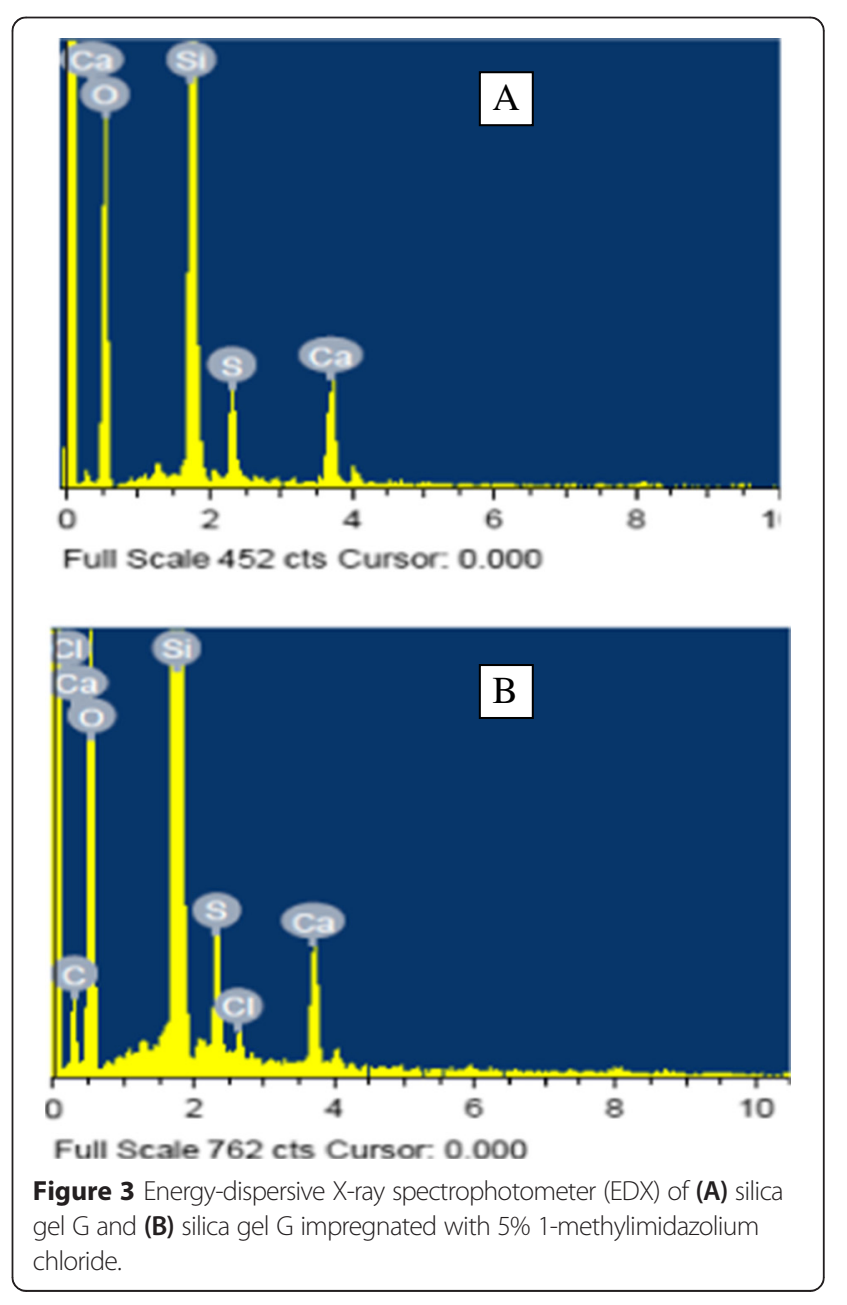




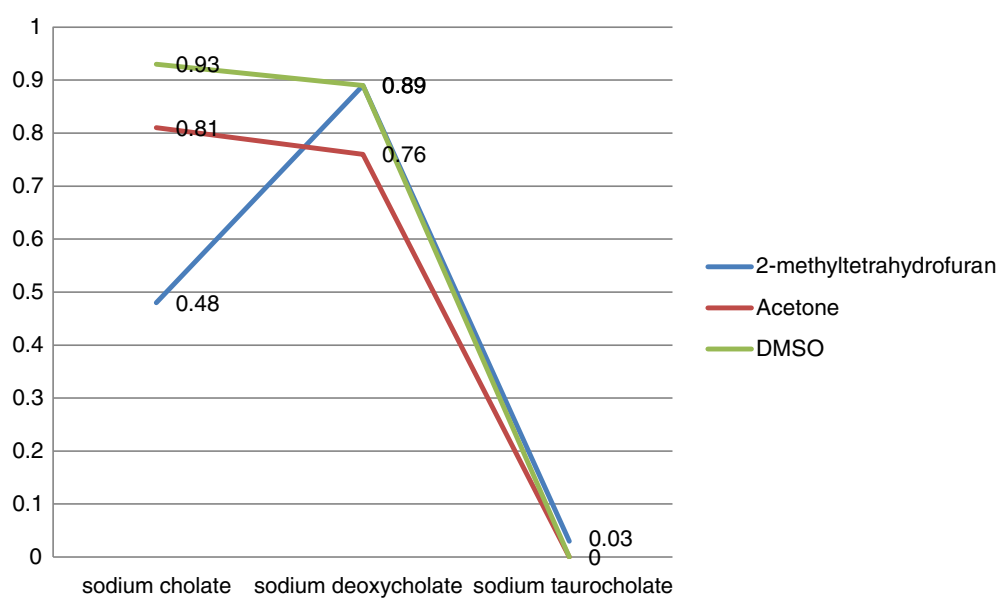

Figure 4 Mobility trend of biosurfactants on $\mathrm{S}_{4}$ as stationary phase with different mobile phases.

alumina and kieselguhr impregnated with the same level of 1-methylimidazolium chloride (5\%). The separation efficacy of different adsorbents towards biosurfactants was in the order silica gel $\mathrm{G}>$ alumina $>$ kieselguhr as evident from Figure 5. It appears that the differences in surface area and activity level of these adsorbents influence the separation pattern. Compared to alumina and kieselguhr (neutral), silica gel (acidic) performs better as stationary phase in the separation of biosurfactants.

\section{G. Effect of interference}

Effect of metal cations, anions, vitamins and amino acids and non-ionic surfactants on the magnitude of separation factor $(\alpha)$ and resolution parameter $\left(R_{\mathrm{s}}\right)$ and $\Delta R_{\mathrm{F}}$ for separation of three-component mixture consisting of SC, SDC and STC has been examined and the results are presented in Tables 6 . From the results, it is clear that magnitude of these parameters is marginally influenced (increases or decreases) in the presence of these foreign substances, but separation was always possible in each case. The minor change in the value of these parameters was due to the slight increase in spot size of the analyte because of certain interactions of biosurfactants with these foreign substances.

H. Limit of detection

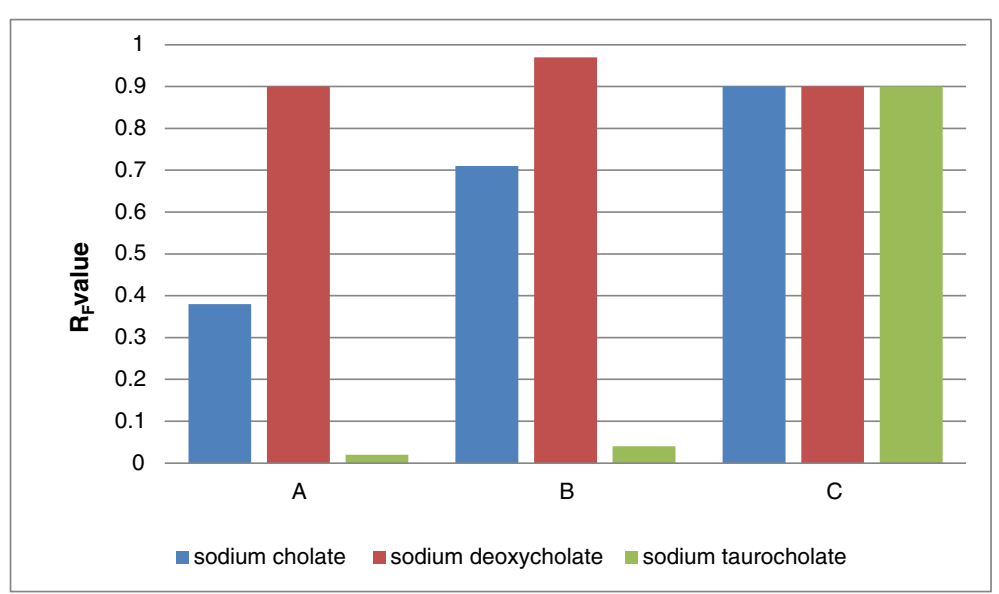

A: Silica gel impregnated with 5\% aq. 1-methylimidazolium chloride

B: Alumina impregnated with $5 \%$ aq. 1-methylimidazolium chloride

C: Kieselguhr impregnated with $5 \%$ aq. 1-methylimidazolium chloride

Figure 5 Effect of stationary phases on $R_{F}$ values of separated surfactants using $\mathrm{M}_{2}$ as mobile phase. 


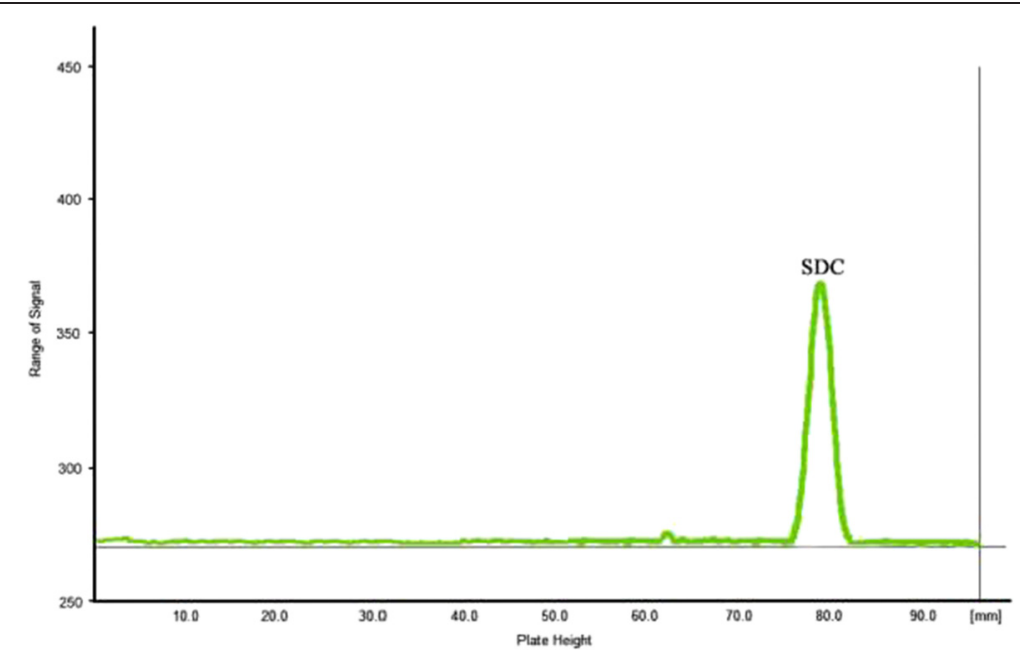

Figure 6 Densitographic presentation for identification of sodium deoxycholate in the mixture of formaldehyde, Triton X-100, Tween 80, sodium deoxycholate.

The lowest possible detectable amounts ( $\mu \mathrm{g} / \mathrm{spot}$ ) of SC, SDC and STC on 5\%(aq) 1-methylimidazolium chloride impregnated silica gel $\left(\mathrm{S}_{4}\right)$ plates developed with $\mathrm{M}_{2}$ (2methyltetrahydrofuran) were $0.7,0.4$ and 3.5 , respectively, showing reasonably good sensitivity of the proposed method for the identification of surfactants at a trace level with preliminary separation from their mixture.

\section{Application}

\section{Composition of Fluarix influenza vaccine}

Each $0.5-\mathrm{mL}$ dose of "Fluarix Influenza Vaccine" contain formaldehyde $(0.05 \mu \mathrm{g})$, Triton X-100 $(0.085 \mu \mathrm{g}), \alpha-$ tocopheryl hydrogen succinate $(0.1 \mathrm{mg})$, Tween 80 (0.415 mg), hydrocortisone $(0.0016 \mathrm{mg})$, gentamicin sulphate $(0.15 \mu \mathrm{g})$, ovalbumin $(0.05 \mu \mathrm{g})$ and sodium deoxycholate $(50 \mu \mathrm{g})$. In order to check the applicability of the proposed method, formaldehyde, Triton X-100, Tween 80 and sodium deoxycholate are mixed; all these are the constituent of this vaccine. Sodium deoxycholate was easily identified in this mixture with the chosen TLC system (Figure 6).

\section{Conclusion}

It can be conclude that the use of 1-methylimidazolium chloride in stationary phase as impregnant and 2methyltetrahydrofuran as mobile phase provides favourable environment for better separation possibilities of biosurfactants. The chosen TLC system was successfully applicable for the identification of sodium deoxycholate in a formulated sample containing the components of influenza vaccine. Another important aspect of this study is the use of green solvent as impregnant in stationary phase in addition to the use of green mobile phase making the proposed TLC system environment friendly.

\section{Abbreviations}

SC: sodium cholate; SDC: sodium deoxycholate; STC: sodium taurocholate; TLC: thin-layer chromatography; ILs: ionic liquids; VOCs: volatile organic compounds; DDW: double-distilled water; DMSO: dimethyl sulfoxide; SEM: scanning electron microscopy; EDX: energy-dispersive X-ray spectrophotometer.

\section{Competing interests}

The authors declare that they have no competing interests.

\section{Author's contributions}

Experimental was done by RM. Both authors equally contributed in experimental design, framing, writing, proofing and approval of the manuscript.

\section{Acknowledgement}

The authors are thankful to the Department of Applied Chemistry and the University Grants Commission, New Delhi, for providing research and financial assistance respectively to both authors who are working as UGC-BSR Faculty Fellow and research scholar.

Received: 16 February 2015 Accepted: 27 April 2015

Published online: 15 May 2015

\section{References}

Gocan S (2002) Stationary phases for thin-layer chromatography. J Chromatogr Sci 40(10):538-549

Hofmann AF, Mysels KJ (1987) Bile salts as biological surfactants. Colloid Surface 30(1):145-173

Kim JB, Lee BW, Yun HJ, Kwon YG (2000) 193-nm Photoresists based on norbornene copolymers with derivatives of bile acid. Chem Lett 29(4):414-415

Mallakpour L, Dinari M (2012) Ionic liquid as green solvents: progress and prospects, in Green chemistry II: properties and application of ionic liquids. Mohammad A, Inamuddin (eds.) Ch. 1, Springer. Dordrecht Heidelberg, New York, London, 1-32

Matarasso A, Pfeifer TM (2009) Mesotherapy and injection lipolysis. Clin Plast Surg 36(2):181-192

Matsuoka K, Moroni Y (2002) Micelle formation of sodium deoxycholate and sodium ursodeoxycholate (part 1). BBA Molecular Cell Biol Lipid 1580(2-3):189-199

Mohammad A, Agrawal V (2001) Separation of amino acids on alumina layers developed with oil-in-water microemulsion. Indian J Chem 40A(10):1130-1134

Mohammad A, Bhawani SA (2008) Silica thin-layer chromatographic studies of surfactants with mixed aqueous-organic eluents containing thiourea: simultaneous separation of co-existing cetyltrimethylammonium bromide, dodecyltrimethylammonium bromide, and polyoxyethylene (20) sorbitan monolaurate. J Chromatogr Sci 46(4):298-303 
Mohammad A, Haq N, Siddiq A (2010) Resolution of multicomponent mixture of amino acids using environmentally benign eluents: a green chromatographic approach. J Sep Sci 33(23-24):3619-3626

Mohammad A, Hina S (2005) Simultaneous separation of nitroaniline isomers with a water-in-oil microemulsion. Acta Chromatogr 15:238-246

Mohammad A, Iraqi E, Khan IA (2002) Use of nonionic poly (ethylene glycol) p-isooctyl-phenyl ether (Triton X-100) surfactant mobile phases in the thin-layer chromatography of heavy-metal cations. J Chromatogr Sci 40(3):162-169

Mohammad A, Siddiq A, Moheman A, El-Desoky GE (2013) Aqueous urea solution promoted resolution of five-component mixture of amino acids on silica TLC plates. J Planar Chromatogr 26(1):31-36

Nanda S (2011) Treatment of lipoma by injection lipolysis. J Cutan Aesthet Surg $4(2): 135-137$

Santhanalakshmi J, Lakshmi GS, Aswal VK, Goyal PS (2001) Small-angle neutron scattering study of sodium cholate and sodium deoxycholate interacting micelles in aqueous medium. Proc Indian Acad Sci (Chem Sci) 113(1):55-62

Selvam S, Andrews ME, Mishra AK (2009) A photophysical study on the role of bile salt hydrophobicity in solubilizing amphotericin B aggregates. J Pharm Sci 98(11):4153-4160

Sodium Cholate, Pierce Biotechnology, USA: http://www.funakoshi.co.jp/data/ datasheet/PCC/89907.pdf.

Touchstone JC (1992) Practice of thin layer chromatography. 3rd edition, John Weily \& Sons, New York

\section{Submit your manuscript to a SpringerOpen ${ }^{\circ}$ journal and benefit from:}

- Convenient online submission

- Rigorous peer review

- Immediate publication on acceptance

- Open access: articles freely available online

- High visibility within the field

- Retaining the copyright to your article

Submit your next manuscript at $>$ springeropen.com 